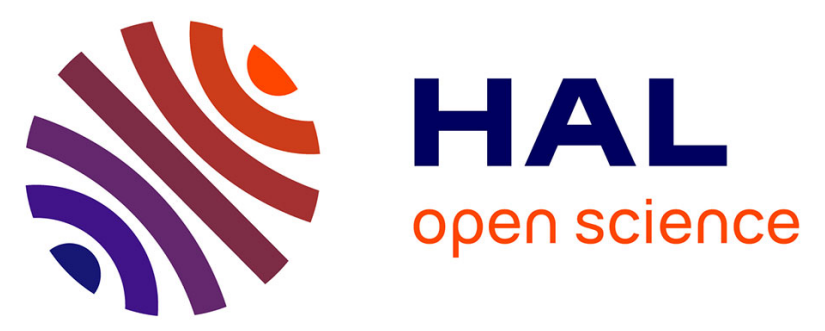

\title{
Gaseous hetero dimers of perfluoro tert-butyl alcohol with hydrogenated alcohols by infrared spectroscopy
}

M. Isabel Cabaço, Marcel Besnard, Pedro Morgado, Eduardo J.M. Filipe, João A.P. Coutinho, Yann Danten

\section{- To cite this version:}

M. Isabel Cabaço, Marcel Besnard, Pedro Morgado, Eduardo J.M. Filipe, João A.P. Coutinho, et al.. Gaseous hetero dimers of perfluoro tert-butyl alcohol with hydrogenated alcohols by infrared spectroscopy. Chemical Physics, 2021, 544, pp.111110. 10.1016/j.chemphys.2021.111110 . hal-03452045

\section{HAL Id: hal-03452045 \\ https://hal.science/hal-03452045}

Submitted on 26 Nov 2021

HAL is a multi-disciplinary open access archive for the deposit and dissemination of scientific research documents, whether they are published or not. The documents may come from teaching and research institutions in France or abroad, or from public or private research centers.
L'archive ouverte pluridisciplinaire HAL, est destinée au dépôt et à la diffusion de documents scientifiques de niveau recherche, publiés ou non, émanant des établissements d'enseignement et de recherche français ou étrangers, des laboratoires publics ou privés. 


\section{Manuscript Details}

\section{Manuscript number}

Title
CHEMPHYS_2020_973

Gaseous hetero dimers of perfluoro tert-butyl alcohol with hydrogenated alcohols by infrared spectroscopy

Full length article

\section{Article type}

\section{Abstract}

Infrared spectroscopy shows that perfluoro tert-butyl alcohol (TBF) forms hydrogen bonded hetero dimers with hydrogenated alcohols (Methanol, 1-butanol and Tert-butanol) in the gas phase at room temperature. DFT calculations confirm these findings providing structures, stabilization energies and allow a first analysis of the vOH spectra by considering only the diagonal term of the anharmonicity of the vibration. The broad band-shapes of vOH vibration of the TBF molecule engaged in the heterodimer are discussed, considering vibrational phase relaxation.

\section{Keywords}

Corresponding Author

Corresponding Author's Institution

Order of Authors

Suggested reviewers
IR spectroscopy Gas Phase; Perfluoro tert-butyl alcohol - hydrogenated alcohols ; H-bonded heterodimers; DFT calculations

Maria Isabel Cabaço

Instituto Superior Tecnico University of Lisbon

Maria Isabel Cabaço, Marcel Besnard, Pedro Morgado, Eduardo Filipe, Joao Coutinho, Yann Danten

Jeanne McHale, Jean-Claude Leicknam, Matthias Heger, Halina Abramczyk, Jannis Samios

\section{Submission Files Included in this PDF}

\section{File Name [File Type]}

letter-editor-CP-12-08.docx [Cover Letter]

Highlights-12-08.docx [Highlights]

graphical-abstract.docx [Graphical Abstract]

Gas-manuscript-12-08.docx [Manuscript File]

declaration-of-competing-interests.docx [Conflict of Interest]

Supporting Information-12-08.docx [Supplementary Material]

To view all the submission files, including those not included in the PDF, click on the manuscript title on your EVISE Homepage, then click 'Download zip file'. 
Dear Editor

We would like to submit our manuscript entitled "Gaseous hetero dimers of perfluoro tert-butyl alcohol with hydrogenated alcohols by infrared spectroscopy" by $\mathrm{M}$. Isabel Cabaço, Marcel Besnard, Pedro Morgado, Eduardo J. M. Filipe, João A. P. Coutinho and Yann Danten for publication at the journal Chemical Physics. Please, find in attached files, the Graphical Abstract, the Highlights and the Supporting Information. This work presents original infrared experimental results showing the formation of gaseous hydrogen-bonded heterodimers of perfluoro tert-butyl alcohol with hydrogenated alcohols (Methanol, 1-butanol and Tert-butanol). The structure of the complexes and the origin of the vibrational relaxation mechanisms in their profiles are discussed. DFT calculations confirmed these findings providing their structures, their stabilization energies and allowing an analysis of the relevant spectral signatures. This study not only gives new physical insights in the field of hydrogen bonding but also model systems well adapted to future active research in the field. We believe that this work represents a significant and original contribution which would be very useful for the Chemical Physics research community.

Sincerely yours,

M. Isabel Cabaço 
Highlights

* H-bonded heterodimers of perfluoro tert-butanol with hydrogenated alcohols

* IR spectroscopy in gas phase

* Inhomogeneous and homogeneous vibrational contributions

* DFT Calculations 


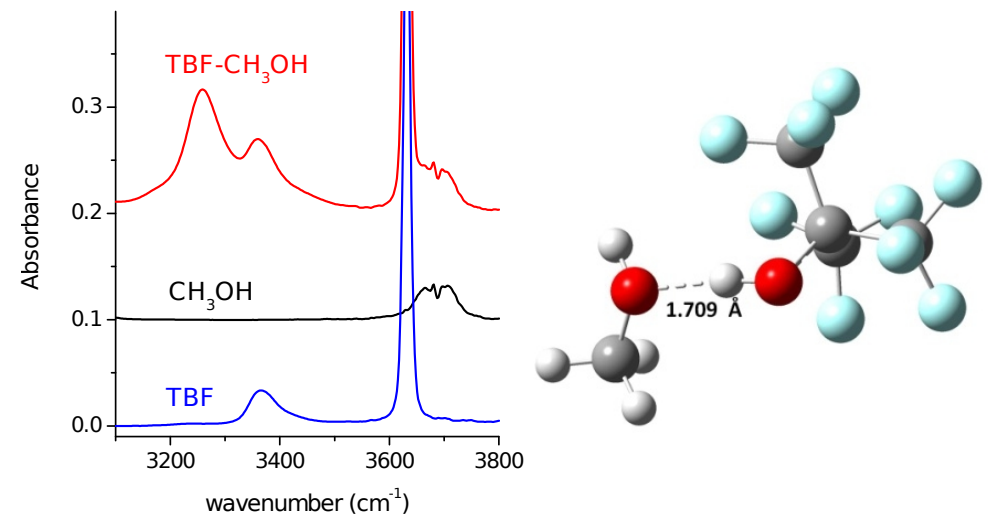


Gaseous hetero dimers of perfluoro tert-butyl alcohol with hydrogenated alcohols by infrared spectroscopy

\section{Isabel Cabaço ${ }^{a, b^{*}}$, Marcel Besnard ${ }^{a, c}$, Pedro Morgado ${ }^{d}$, Eduardo J. M. Filipe ${ }^{d}$, João A. P. Coutinho ${ }^{\mathrm{e}}$ and Yann Danten ${ }^{\mathrm{c}}$}

${ }^{a}$ CeFEMA, Department of Physics, Instituto Superior Técnico, Universidade de Lisboa, 1049-001 Lisboa, Portugal

${ }^{b}$ Laboratório de Instrumentação, Engenharia Biomédica e Física da Radiação (LIBPhys-UNL), Departamento de Física, Faculdade de Ciências e Tecnologia, FCT, Universidade Nova de Lisboa, Caparica, Portugal

${ }^{c}$ GSM Institut des Sciences Moléculaires, CNRS (UMR 5255), Université Bordeaux I,351, Cours de la Libération 33405 Talence Cedex, France

${ }^{d}$ Centro de Química Estrutural, Instituto Superior Técnico, Universidade de Lisboa, 1049-001 Lisboa, Portugal

${ }^{e}$ CICECO, Departamento de Química, Universidade de Aveiro 3810-193 Aveiro, Portugal

*Corresponding author: M. I: Cabaço, e-mail: isabelcabaco@tecnico.ulisboa.pt 


\begin{abstract}
Infrared spectroscopy shows that perfluoro tert-butyl alcohol (TBF) forms hydrogen bonded hetero dimers with hydrogenated alcohols (Methanol, 1-butanol and Tertbutanol) in the gas phase at room temperature. DFT calculations confirm these findings providing structures, stabilization energies and allow a first analysis of the $v_{\mathrm{OH}}$ spectra by considering only the diagonal term of the anharmonicity of the vibration. The broad band-shapes of $v_{\mathrm{OH}}$ vibration of the $\mathrm{TBF}$ molecule engaged in the heterodimer are discussed, considering vibrational phase relaxation.
\end{abstract}

\title{
Keywords
}

IR spectroscopy Gas Phase

Perfluoro tert-butyl alcohol - hydrogenated alcohols

H-bonded heterodimers

DFT calculations

\section{Introduction}

Spectroscopic studies of hydrogen bonded dimers $\mathrm{AH} \cdots \mathrm{B}$ in the gas phase at low pressure is a well-established research field. A central reason is that working under such experimental conditions leads to the determination of intrinsic properties of the dimers, avoiding complications arising from the interactions with the solvent and/or the competing formation of various oligomers in the liquid phase [1-2]. Such an approach allows, directly, the investigation of interactions between the $\mathrm{AH}$ and $\mathrm{B}$ moieties. Two systems remain as paradigms in this field; namely $\mathrm{HCl}$ - dimethyl ether and $\mathrm{HCl}$ acetic acid. The gas phase dimers of these systems have long been thoroughly investigated by vibrational spectroscopy and continue to be scrutinized at a higher level of theory [3-22]. The formation of homo and hetero clusters of alcohols and H-bond donor molecules have been also investigated using a variety of spectroscopic techniques such as cooled in a low temperature matrix, dilution in a solvent, expansion in supersonic slit jets, and also theoretically [12-17,23-69].

This study proposes a new, convenient and easy way to prepare alcohol hetero dimers, thus opening a range of new systems of H-bonding investigations. The main idea is to use perfluoro tert-butanol (TBF) as the H-bond donor, interacting with the oxygen atom of a hydrogenated acceptor. The strategy is based on the strongly acidic character of the TBF molecule $(\mathrm{pKa}=5.4)$ [70] resulting from the electron withdrawing effect of the fluoride substituents, whereas the selected hydrogenated alcohols are comparatively 
strongly basic (average pKa about 16) [71]. It is thus anticipated that the hetero dimer will be $\left(\mathrm{CF}_{3}\right)_{3} \mathrm{COH}---\mathrm{OHR}$, enabling rationalizing the hetero-dimer as a super triatomic molecule AH $\cdots \mathrm{B}$ [20]. The selected hydrogenated molecules are: tert-butyl alcohol $\left(\left(\mathrm{CH}_{3}\right)_{3} \mathrm{COH}, \mathrm{pKa}=16.54\right.$ [72] referred here as $\left.\mathrm{TBH}\right)$ with a globular geometry similar to TBF; 1-butanol ( $\mathrm{pKa}=16.1$ [72]) with a linear geometry but the same mass as $\mathrm{TBH}$; and methanol $\left(\mathrm{CH}_{3} \mathrm{OH}, \mathrm{pKa}=15.5\right.$ [72] $)$ the simplest alcohol with a mass half that of TBH.

This work is also part of a wider project in which we study mixtures of hydrogenated and fluorinated substances; alcohols [73-76] in particular.

\section{Experimental conditions}

TBH, methanol, 1-butanol and TBF originated from Sigma-Aldrich and Apollo, respectively (purity greater than 99\%), as well as $\mathrm{CD}_{3} \mathrm{OH}$ and tert-butanol-D9 $\left(\mathrm{CD}_{3}\right)_{3} \mathrm{COH}$ (TBD9) from Eurisotop (purity 98\%) were dried using molecular sieves (3 Á). The water content of all the chemicals was measured by Karl-Fisher titration and found to be $400 \mathrm{ppm}$.

The infrared spectra were measured on a Bruker-Alpha FT-IR spectrometer with a $4 \mathrm{~cm}^{-}$ ${ }^{1}$ resolution in the spectral range $400 \mathrm{~cm}^{-1}$ to $4000 \mathrm{~cm}^{-1}$ after collecting 64 scans. The experiments were performed using a $7 \mathrm{~cm}$ path-length gas cell with $\mathrm{ZnSe}$ windows, which was purged with argon before each experiment. The sample preparation consisted of boiling a few drops of the desired pure alcohol or mixture inside an argon filled glass flask, followed by adding a few milliliters of this vapour phase (10 Torr) to the spectrometer gas cell using a hypodermic syringe. All the experiments were performed at $298 \mathrm{~K}$.

The DFT calculations were carried out using the program Gaussian09.D01 package [77]. All the structures of homo and hetero oligomers of the hydrogenated alcohols and/or TBF molecules were achieved using the Generalized Gradient Approximation (GGA)hybrid functional B3LYP with the $6-311+\mathrm{G}(2 \mathrm{~d}, \mathrm{p})$ basis set. The vibrational analysis was performed using the standard Wilson FG matrix formalism based on the harmonic force field approximation [78]. Then, an additional anharmonic vibrational analysis was performed at the same computational level for determining the anharmonicity of the vibrations in monomers and dimers [79]. In the present investigation, we are particularly focussing on the anharmonicity of both $v_{\mathrm{OH}}$ stretching and $\gamma_{\mathrm{OH}}$ torsional 
modes of monomers and hetero dimers of hydrogenated alcohols and TBF species. The structural and vibrational calculated properties are gathered in SI (Tables SI-1-4). The calculated energies (electron energy and binding energy) are given in Table SI-1 and the predicted vibrational properties of the $v_{\mathrm{OH}}$ stretching and $\gamma_{\mathrm{OH}}$ torsion modes are gathered in Tables SI-2-3.

\section{Experimental results}

We will first consider the infrared spectra of the TBF-methanol equimolar binary mixture as representative of the different systems studied here, focusing the attention in the domain of the $v_{\mathrm{OH}}$ vibration $\left(3100-3800 \mathrm{~cm}^{-1}\right)$. The very low pressure gaseous spectra at room temperature of pure $\mathrm{TBF}$, pure methanol and of their mixture are reported in Figure 1. In this spectral domain, the $v_{\mathrm{OH}}$ vibration of monomeric TBF is given by a rather intense and narrow single line centered at about $3632 \mathrm{~cm}^{-1}$ having a full width at half-height (FWHH) of about $13 \mathrm{~cm}^{-1}$. A weaker line centered at about $3365 \mathrm{~cm}^{-1}$ and having a FWHH of $60 \mathrm{~cm}^{-1}$ is also observed; and can be assigned to a negative combination band of the $v_{\mathrm{OH}}$ vibration with the $\gamma_{\mathrm{OH}}$ vibration [23]. We also note that TBF is a very poorly associated liquid $[23,35]$ ruling out any doubt concerning the conclusion that monomeric species are observed here in gas phase at low pressures. In the case of methanol, the infrared spectra displays a single band centered at about 3681 $\mathrm{cm}^{-1}$ with a band shape characteristic of the envelop of the ro-vibrational structure encountered in gaseous phase for monomeric alcohols [29,41,62].
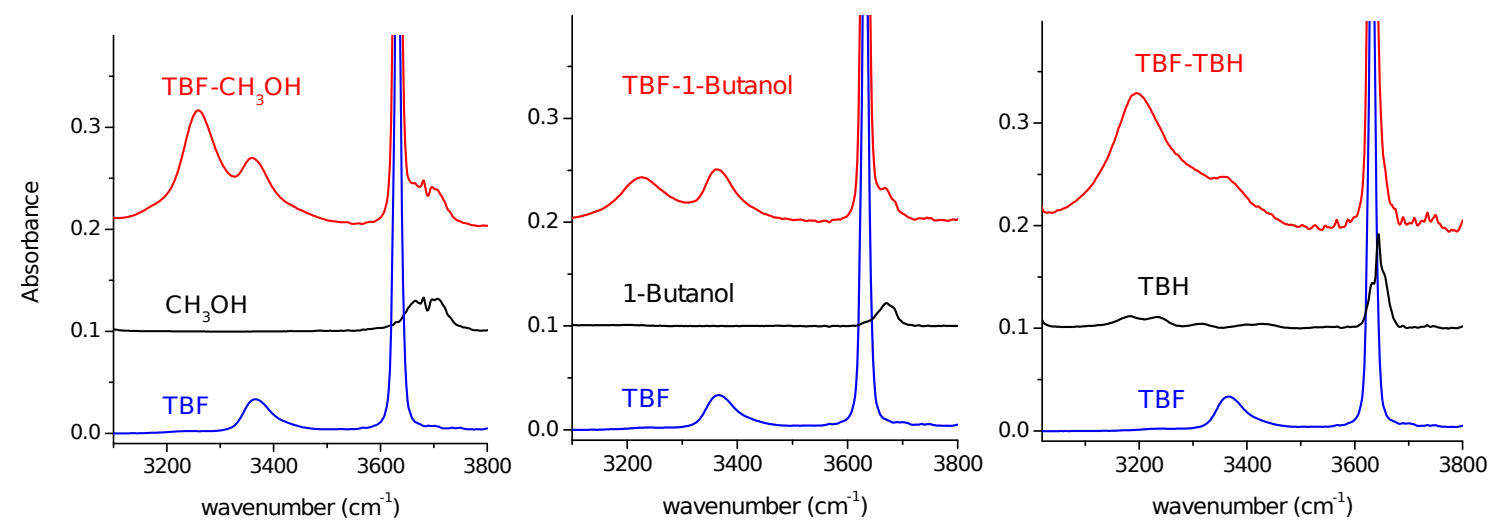

Figure 1. Infrared spectra in the domain of the $\mathrm{OH}$ stretching vibration of the gaseous mixtures TBF- $\mathrm{CH}_{3} \mathrm{OH}$, TBF-1-butanol and TBF-TBH compared with the spectra of their pure components. 
As for the equimolar mixture of TBF and methanol, two main observations can be made. First of all, a single line is observed at about the frequency of the $v_{\mathrm{OH}}$ vibration of monomeric TBF, but with a slightly broader width $\left(14 \mathrm{~cm}^{-1}\right)$, which superimposes distorting the low frequency side of the band of monomeric methanol. The second observation concerns the emergence circa $3258 \mathrm{~cm}^{-1}$ of a new broad band (FWHH of about $70 \mathrm{~cm}^{-1}$ ) inexistent in the two pure alcohols. We also notice that the combination mode reported for pure TBF is slightly affected in the mixture. This band is slightly redshifted and becomes broader (Table 1).

Table 1. Experimental band center frequencies and Full Widths at Half-Height $\left(\mathrm{cm}^{-1}\right)$ of the Infrared spectra at room temperature of gaseous phase of equimolar mixtures of TBF with hydrogenated alcohols in the spectral domain of the $v_{\mathrm{OH}}$ stretching vibrations. Anharmonic vibrational transitions and infrared intensities $(\mathrm{km} / \mathrm{mol})$ of these vibrations obtained from DFT calculations at the B3LYP/6-311+G(2d,p) computational level.

\begin{tabular}{|c|c|c|c|c|c|c|}
\hline \multirow[t]{3}{*}{ Species } & \multicolumn{4}{|c|}{ Experimental } & \multirow{2}{*}{\multicolumn{2}{|c|}{ Calculated }} \\
\hline & \multirow[b]{2}{*}{$v$} & \multirow[b]{2}{*}{ FWHH } & \multicolumn{2}{|c|}{$\begin{array}{c}\text { Combination } \\
v_{\mathrm{OH}}-\gamma_{\mathrm{OH}}\end{array}$} & & \\
\hline & & & $v$ & FWHH & $v$ & Intensity \\
\hline Monomers & & & & & & \\
\hline TBF & 3632 & 12.8 & 3365 & 60 & 3612.5 & 83.3 \\
\hline TBH & 3643 & 24 & & & 3644.9 & 11.8 \\
\hline TBD9 & 3643 & 26 & & & 3644.5 & 10.3 \\
\hline 1-Butanol & 3671 & 38 & & & 3670.6 & 25.6 \\
\hline $\mathrm{CH}_{3} \mathrm{OH}$ & 3681 & 85 & & & 3655.9 & 26.6 \\
\hline $\mathrm{CD}_{3} \mathrm{OH}$ & 3682 & 69 & & & 3655.9 & 26.2 \\
\hline \multicolumn{7}{|l|}{ Hetero-dimers } \\
\hline TBF-TBH & $\begin{array}{l}3632 \\
3197 \\
\end{array}$ & $\begin{array}{c}15 \\
110\end{array}$ & 3363 & 90 & $\begin{array}{l}3624.9 \\
3034.1\end{array}$ & $\begin{array}{c}23.1 \\
641.0\end{array}$ \\
\hline TBF-TBD9 & $\begin{array}{l}3632 \\
3195 \\
\end{array}$ & $\begin{array}{c}14 \\
120 \\
\end{array}$ & 3359 & 100 & $\begin{array}{l}3627.6 \\
3042.7\end{array}$ & $\begin{array}{c}23.2 \\
620.3\end{array}$ \\
\hline TBF-1-Butanol & $\begin{array}{l}3632 \\
3226\end{array}$ & $\begin{array}{l}14 \\
98\end{array}$ & 3363 & 76 & $\begin{array}{l}3652.6 \\
3041.3\end{array}$ & $\begin{array}{c}37.1 \\
467.7\end{array}$ \\
\hline $\mathrm{TBF}-\mathrm{CH}_{3} \mathrm{OH}$ & $\begin{array}{l}3632 \\
3258 \\
\end{array}$ & $\begin{array}{l}14 \\
74\end{array}$ & 3360 & 78 & $\begin{array}{l}3648.3 \\
3123.7 \\
\end{array}$ & $\begin{array}{c}42.2 \\
892.3\end{array}$ \\
\hline TBF-CD ${ }_{3} \mathrm{OH}$ & $\begin{array}{l}3632 \\
3256\end{array}$ & $\begin{array}{l}14 \\
82\end{array}$ & 3359 & 96 & $\begin{array}{l}3649.3 \\
3117.8\end{array}$ & $\begin{array}{c}42.9 \\
890.5\end{array}$ \\
\hline
\end{tabular}

We have also performed the same type of measurements on the mixture TBF deuterated methanol $\left(\mathrm{CD}_{3} \mathrm{OH}\right)$. The results obtained show that there are almost no differences with the mixture involving hydrogenated methanol (Table 1). Considering 
now the TBF-TBH and TBF-1-butanol binary mixtures, we can see on Figure 2 that they present the same trend reported above for the TBF-methanol mixture. We notice that the intense and narrow line. observed in the two mixtures. is approximately centered at the wavenumber of that observed in pure TBF. Again a new broad band is observed in the two mixtures and we also notice that the band center and width of the combination band is slightly affected upon mixing. The spectra of these mixtures and their pure components are displayed in Figure 1.

We have also studied the mixture of TBF with deuterated TBH (TBD9). We found that there was also very slight variation compared to the TBF-TBH mixture (Table 1) as it was found for TBF-deuterated methanol (Figure SI.1). The ensemble of experimental results namely band center frequencies and FWHH measured in all the different systems are reported for comparison in Table 1.

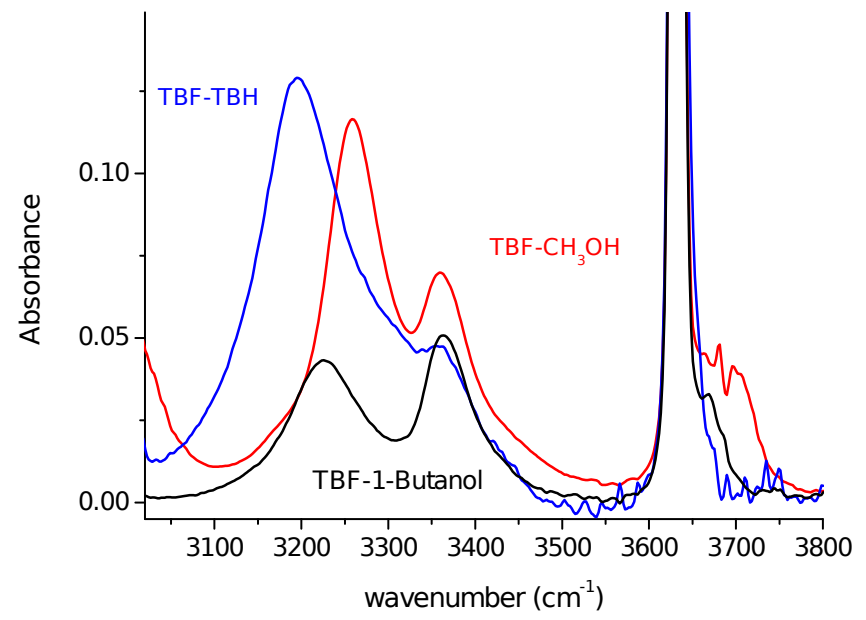

Figure 2. Infrared spectra in the domain of the $\mathrm{OH}$ stretching vibration of the gaseous mixtures of TBF with hydrogenated alcohols

From these experimental observations, we can conclude without any ambiguity that the new band observed in all these systems can be assigned to the $v_{\mathrm{OH}}$ vibration of the TBF molecule interacting with the hydrogen alcohol to form a 1:1 heterodimer. More specifically, in all cases, the TBF molecule is the proton donor: the hydrogen atom of its hydroxyl group interacts with the oxygen atom of the hydrogenated alcohol molecule, the acceptor center. This assignment of a $\mathrm{OH} \cdots \mathrm{O}$ hydrogen bond formation is also confirmed by the large red-shift experienced by the $v_{\mathrm{OH}}$ vibration of TBF compared with its value in the monomer molecule.

We also notice that the $v_{\mathrm{OH}}$ vibration of the hydrogenated alcohol molecule (the proton acceptor in the hetero-dimer) corresponding to the terminal hydroxyl group of the $\mathrm{H}$ - 
bonded alcohol may be superimposed here with the band of the monomers. The frequency of this terminal $\mathrm{OH}$ group is so close to that of the non-reacted monomers that the corresponding lines overlap badly and are not resolved.

The comparison of the frequencies of the $v_{\mathrm{OH}}$ vibration of the different heterodimers shows that, although having very close values, nevertheless slightly increase from TBH to 1-Butanol and to methanol. This trend suggests that the strength of the H-bond interaction increases along the sequence Methanol $<$ Butanol $<\mathrm{TBH}$. This is consistent with the $\mathrm{pKa}$ values of the different species previously mentioned. Indeed, although the basicity of the three hydrogenated alcohols is not drastically different, thus leading to $v_{\mathrm{OH}}$ vibrations within the same range, the values of the vibration frequencies follow the basicity order. We notice that the broadening (FWHH) of the donor $v_{\mathrm{OH}}$ vibration follows the same order. Moreover the observed trend in both variables (frequency shift and width) appears linear (Figure SI.2). In this context, it is important to mention that we have also studied mixtures of TBH-1-butanol and TBH-methanol, in which the components have very similar basicity. For these mixtures, we have not able to identify any hetero-dimers, a result in marked contrast with those reported here. This clearly reveals the importance of the 'acidic' character of the TBF molecule in the formation of hetero dimers.

To complete the experimental characterization of the different heterodimers, we have resorted to the empirical scale, still widely used in the context of the hydrogen bonding interaction, correlating the shift of the $v_{\mathrm{OH}}$ stretching frequency to the $\mathrm{H} \cdots \mathrm{O}$ distance in hydrogen bonds. [80-85]. Taking the average value of the $v_{\mathrm{OH}}$ vibration as $3220 \mathrm{~cm}^{-1}$ for the three systems, we found that the $\mathrm{OH} \cdots \mathrm{O}$ distance is $1.7 \AA$.

\section{Discussion}

DFT calculations were performed in order to better characterize the geometry and spectral features of the three hetero dimers. It is found that these entities have rather similar structures involving the proton of the $\mathrm{OH}$ hydroxyl group of $\mathrm{TBF}$ as the hydrogen bond donor and the oxygen atom of the hydrogenated alcohols as acceptor (Figure 3). These results confirm the experimental inference about the roles played by the TBF and the hydrogenated alcohol molecule in the complex formation. The calculated $\mathrm{OH} \cdots \mathrm{O}$ distances have been found very close for the three systems with a

value of about $1.7 \AA$. This feature is in perfect agreement with that obtained from the 
empirical relationship discussed previously. It was even noticed that the calculated $\mathrm{OH} \cdots \mathrm{O}$ distance is found to decrease slightly according to the sequence Methanol > Butanol $>$ TBH. This trend is in complete agreement with the result concerning the strength of the hydrogen bond interaction discussed in the experimental section.

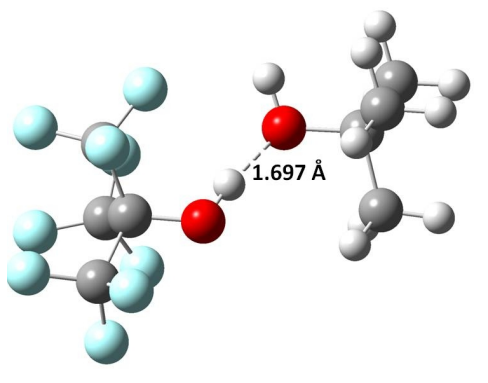

$-9.7 \mathrm{kcal} / \mathrm{mol}$.

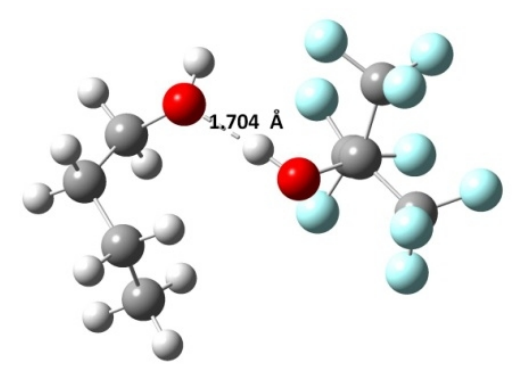

$-9.3 \mathrm{kcal} / \mathrm{mol}$.

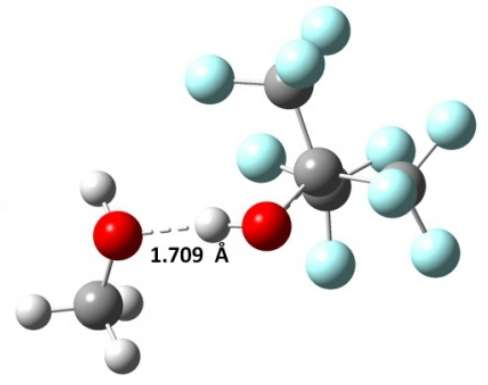

$-9.3 \mathrm{kcal} / \mathrm{mol}$.

Figure 3. Geometry and binding energy corrected from the BSSE obtained from DFT calculations at the $\mathrm{B} 3 \mathrm{LYP} / 6-311+\mathrm{G}(2 \mathrm{~d}, \mathrm{p})$ computational level for the hetero-dimers in gas phase. From left to right TBF-TBH, TBF-1-Butanol, TBF- $\mathrm{CH}_{3} \mathrm{OH}$.

The calculated stabilization energies of the hetero dimers corrected from the BSSE contribution are found rather similar for the three complexes (Figure 3) and confirm that the TBF-TBH complex is slightly more stable than the two other systems.

Having characterized the structural and energetic aspects of the complex we have tried to analyze comparatively their infrared spectra. Prior to a discussion of the results we would like to make some comments. In the theoretical treatments of the infrared spectra, the complex is considered to be a linear super triatomic molecule $\mathrm{AH} \cdots \mathrm{B}$, for which the high frequency $v_{\mathrm{AH}}$ vibration and the low frequency $v_{\mathrm{AH}} \cdots_{\mathrm{B}}$ vibration are coupled by an anharmonic potential $[3,4,11,12,19,22,86-92]$. Vibrational transitions from different levels of the low-frequency oscillator in the $v_{\mathrm{AH}}=0$ state to different low-frequency levels in the $v_{\mathrm{AH}}=1$ state with a shifted origin of the potential result in a progression of lines which for moderate displacements is centered at the pure AH stretching transition and displays a mutual line separation by one quantum of the low frequency mode (the so-called Franck- Condon type progression in the literature). An examination of the band-shape of the spectra of the dimers of the systems reported here does not show any type of such progression. The band of the dimer appears to be unique. However, as will be addressed later (as to the physical origin of the profile), we may wonder whether, in this band, there are some faint contributions which may be assigned to combination modes of the $v_{\mathrm{OH}}$ transition with rocking modes of $\mathrm{CF}_{3}$ groups. It seems that in the region of interest the only effect of the $\mathrm{H}$ bond interaction is to slightly broaden the 
negative combination existing between the $\mathrm{OH}$ stretching vibration and the low frequency $\mathrm{OH}$ torsion (Table 1). Therefore, in a first approach, we will admit as a working hypothesis that the band of the complex is a single one and not a superimposition of the Franck-Condon type progression mentioned previously.

On the basis of this hypothesis, we have resorted to DFT calculations considering only the anharmonicity of the $v_{\mathrm{OH}}$ vibration and neglected any possible coupling with a lower vibration. We must also emphasize that a deeper treatment considering the interaction of the modes based upon the calculation of the full potential energy surface (PES) will be too demanding, from the point of view of computer resources, for the rather big molecules considered here.

We have first of all calculated for TBF and the hydrogenated monomers the frequency of the $v_{\mathrm{OH}}$ vibration and found a nice agreement with the experimental values (Table 1). We have then calculated the values of the $v_{\mathrm{OH}}$ vibrations of the terminal $\mathrm{OH}$ group of the dimers and the $v_{\mathrm{OH}}$ vibration of the hydroxyl group of $\mathrm{TBF}$ as an $\mathrm{H}$ bond donor (Table 1). The calculated frequencies of the terminal $\mathrm{OH}$ values overestimate the experimental values (about $0.2-0.4 \%$ ) whereas the contrary is observed for the $v_{\mathrm{OH}}$ vibration of the hydroxyl group in the complex (about 3-6\%). Therefore we should admit that the agreement obtained between calculations and experimental results can be only considered as fair. However, we note that the calculated frequencies values show that the strength of the $\mathrm{H}$-bond interaction increases according to the trend already reported, i.e., Methanol $<$ Butanol $<$ TBH. In view of the working hypothesis, this result which is consistent with the experimental observation can be considered as rather satisfying. A better numerical agreement certainly will rely on considering not only diagonal anharmonic coefficient but also the non-diagonal coefficients as has been underlined in recent studies $[22,65,91,92]$.

The last point which merits to be discussed concerns the origin of the large broadening (circa $100 \mathrm{~cm}^{-1}$ ) of the heterodimer band shape (Table 1). Such large broadening is again a signature of $\mathrm{H}$-bond. In the liquid state, this broadening generally results from the modulation of the interatomic $\mathrm{OH} \cdots \mathrm{O}$ vibration due to the interaction with the thermal bath leading in turn to the broadening of the coupled $v_{\mathrm{OH}}$ high frequency vibration [93]. This mechanism cannot be considered here due to the lack of thermal bath. Under the thermodynamic conditions of the gas phase experiment performed here only collisions between molecules are possible. The corresponding mean time between 
collisions being in the nanosecond time scale this cannot explain the sub-picosecond scale corresponding to the large broadening observed.

Therefore, we will try to discuss the observed broadening on the bandshape of the $v_{\mathrm{OH}}$ profile of the TBF donor molecule on the ground of physical considerations.

The shape of the infrared profile results from the convolution of a vibrational profile by a rotational one if the vibrational and reorientational dynamics are independent $[12,94,95]$. However, we can discard the importance of the rotational contribution in the bandshape of the $v_{\mathrm{OH}}$ profile of the TBF H-bond donor molecule according to the following line of reasoning. In gas phase, at the low pressure of the experiment (a few $\mathrm{Hg} \mathrm{mm}$ ), the molecule is freely rotating. Considering the TBF monomer, we found that the $v_{\mathrm{OH}}$ profile is given by a single line having a broadening of about $10 \mathrm{~cm}^{-1}$ after correction of the finite effect of the resolution (Figure SI.3). Let us assume that this profile is only the envelope of the rotational structure and that the vibrational contribution is negligible. When the TBF molecule is engaged in a complex, the rotational contribution would be strongly hindered and its contribution in the infrared profile would be much smaller than that of the freely rotating molecule. The broadening of the $v_{\mathrm{OH}}$ profile of TBF in the complex is about $100 \mathrm{~cm}^{-1}$ and therefore much greater than that due to the rotational contribution,which should be less than $10 \mathrm{~cm}^{-1}$. Thus, we can safely infer that the shape and broadening of the $v_{\mathrm{OH}}$ profile of TBF in the complex mostly provides information on the vibrational phase relaxation.
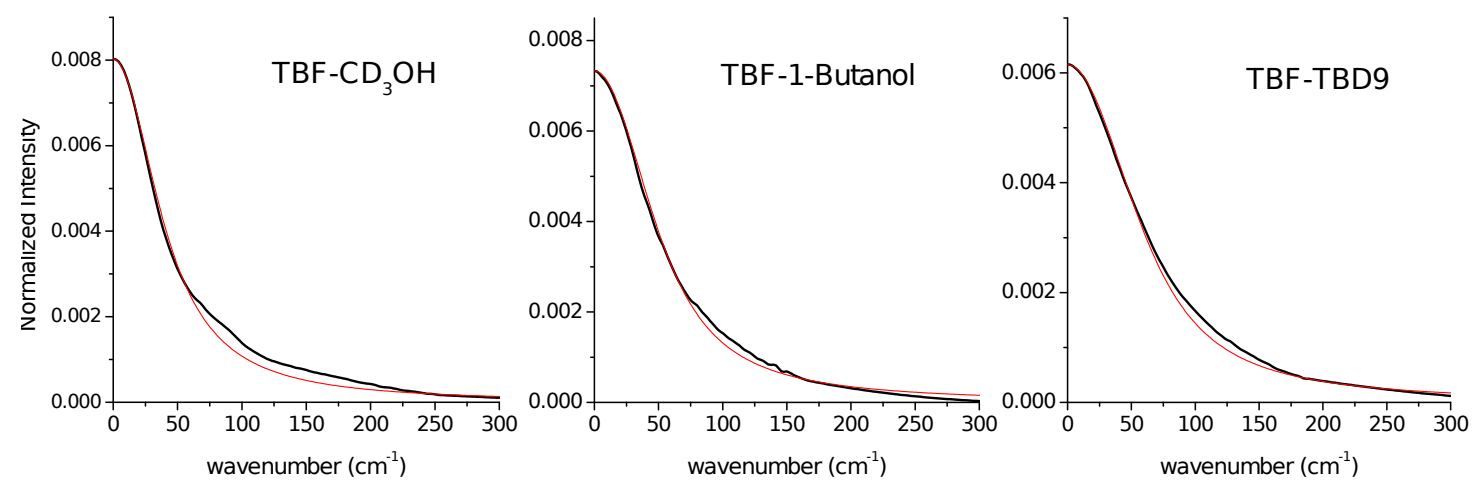

Figure 4. Comparison of the experimental symmetrized band-shapes (see text) of the $\mathrm{OH}$ stretching vibration of the mixtures (black) with that calculated using the Voigt profile (red).

We have checked that the $v_{\mathrm{OH}}$ profile of the TBF donor molecules engaged in the heterodimers is neither Gaussian nor Lorentzian, but they could be nicely described by a Voigt profile which results from the convolution of a Gaussian by a Lorentzian. This is 
illustrated on Figure 4. Interestingly, we found that the contributions to the width of the experimental bandshapes by the Gaussian and Lorentzian profiles are of the same order of magnitude (Table SI.5). Such a result suggests that the inhomogeneous and the homogeneous contributions associated to Gaussian and Lorentzian profiles, respectively, are both present in the experimental bandshapes. However, such simple analysis does not seriously allow disentangling the relative importance of the two processes in the bandshape, but merely indicate that both processes may be involved in the vibrational relaxation mechanism. We may speculate that the inhomogeneous contribution corresponds to a broad continuous distribution of different $v_{\mathrm{OH}}$ transition frequencies reflecting a rather-continuous variation of hydrogen bonds configurations. The origin of the homogeneous contribution is more difficult to assess but the corresponding linewidth could be associated with rapid variations in the angle and length of the local O$\mathrm{H} \cdots \mathrm{O}$ hydrogen bonds [96]. We may also suspect that the homogeneous contribution is correlated with intra-molecular vibrations due to anharmonic coupling. A support to this statement may be suggested by the fact that the combination of the $\mathrm{OH}$ torsion with the $v_{\mathrm{OH}}$ mode existing in pure TBF is affected (and in particular its width, see Table 1) upon mixing with the hydrogenated alcohol. However, in the absence of more information and calculations aimed at studying the effects of the diagonal and non-diagonal anharmonicity terms, a deep interpretation of the homogeneous contribution remains speculative.

\section{Conclusion}

We have shown that fluoro tert-butyl alcohol (TBF) can form easily complex in the gas phase at RT with a variety of hydrogenated alcohols such as methanol, butanol, tertbutanol and some of their deuterated derivatives. In all these systems, it is found that the molecules interact via the formation of an $\mathrm{OH} \cdots \mathrm{O}$ hydrogen bond between the proton of the hydroxyl group of the fluorinated molecule, playing the role of $\mathrm{H}$-bond donor, with the oxygen atom of the hydroxyl group of the hydrogenated alcohol as acceptor. This conclusion is reached from the observation in the $v_{\mathrm{OH}}$ region of the infrared spectra of a new band in the TBF-hydrogenated alcohol mixtures. This band ís not detected in the spectra of the separate alcohols, and presents the signatures of H-bonding (i.e., a strong red-shift of the band from those of the monomers, a relatively strong intensity and a large broadening). It is inferred on the basis of the red shift values and using empirical 
relation used in $\mathrm{H}$-bond investigations to specify the $\mathrm{O}-\mathrm{H} \cdots \mathrm{O}$ intermolecular distance that the strength of the H-bond interaction, although not very different, increases in the three hetero dimers according to the sequence TBH $>1$-Butanol $>$ Methanol. DFT calculations confirm the formation of these hetero-dimers by specifying their structure and energy of formation. These calculations have been also aimed at studying the infrared spectra of the $v_{\mathrm{OH}}$ stretching band. Considering only the diagonal anharmonic coefficient of the $\mathrm{OH}$ vibration, the calculations are found in a remarkable agreement with those measured for the monomers species. However, they only give the correct trend experimentally observed for the values of the $v_{\mathrm{OH}}$ band of TBF in the dimer, but without good numerical agreement. This shows that, in the domain of hydrogen bonding, the need to take into account the non-diagonal anharmonicity term is important. Finally, the profile of the $v_{\mathrm{OH}}$ stretching band of the $\mathrm{H}$ bond donor TBF was analyzed using a Voigt profile. This approach suggests that two processes would contribute to the broadening. An inhomogeneous contribution resulting from the distribution of the $v_{\mathrm{OH}}$ transition frequencies, reflecting a rather continuous variation of hydrogen bond configurations, and a homogeneous contribution, which is likely associated with rapid variations in the angle and length of the local $\mathrm{O}-\mathrm{H} \cdots \mathrm{O}$ hydrogen bond and may be correlated with intra-molecular vibrations due to anharmonic coupling.

In conclusion, we guess that the systems here studied could be also considered as model systems in the domain of hydrogen bonding. And as such they merit a deeper examination. The bands are rather unique, apparently, and without the complication of sub-structure and therefore might be of interest for comparison with the deep analytical theories [14,22]. Similarly, the role of non-diagonal anharmonicity, which is a research field of current interest, has been only explored as far as we know on pure alcohol clusters. In this context, the studies of hetero alcoholic clusters would certainly enable an interesting extension $[65,90]$. Finally, we believe that these systems merit to be tackled with time-resolved spectroscopy [97-99].

\section{Acknowledgments}

The authors are pleased to thank Professor Laura Ilharco and Marta Coelho for providing infrared facilities. We are indebted to Professor Jack Yarwood for critically reading the manuscript, for his comments and useful discussions. 
The authors gratefully acknowledge the support provided by the HPC resources and allocations of computing time from GENCI (IDRIS) and the facilities of the Mesocentre de Calcul Informatique Aquitain (MCIA) of the University of Bordeaux and des Pays de l'Adour. The authors acknowledge the finantial support from FCT/MEC through the project CICECO-Aveiro Institute of Materials, UIDB/50011/2020 \& UIDP/50011/2020 and when appropriate co-financed by FEDER under the PT2020 Partnership Agreement.

\section{References}

[1] C. Legon, D. J. Millen, Directional Character, Strength and Nature of the Hydrogen Bond in Gas-Phase Dimers, Acc. Chem. Res. 20 (1987)39-46.

[2] D. J. Millen, J. Molec. Structure 100 (1983) 351-377

[3] S. Bratož, D. Hadži, Infrared Spectra of Molecules with Hydrogen Bonds, J. Chem. Phys. 27 (1957) 991.

[4] N. Sheppard, Infrared Spectroscopy and Hydrogen Bonding - Band Width and Frequency Shifts in: Hydrogen bonding, D. Hadzi (Ed.), Pergamon Press, 1959, p. 85-105.

[5] J.-C. Lassègues and P. V. Huong, Infrared Spectrum of the Gaseous ClH...O $\left(\mathrm{CH}_{3}\right)_{2}$ Complex, Chem. Phys. Lett. 17 (1972) 444-446.

[6] J. Yarwood, in: J. Yarwood (Ed.), Spectroscopy and Structure of Molecular Complexes, Springer, 1973, p. 105.

[7] Y. Bouteiller and E. Maréchal, Etude Théorique du Spectre Infra-rouge des Complexes liés par Liaison Hydrogène à l'État Gazeux: Complexe $\mathrm{ClH} \ldots \mathrm{O}\left(\mathrm{CH}_{3}\right)_{2}$, son Homologue Deutérié et Complexes Voisins, Mol. Phys. 32 (1976) 277-288.

[8] C. Perchard, J. P. Perchard, Liaison Hydrogène en Phase Liquide et Spectrométrie Raman. III-Structure et Intensité de la Bande $v(\mathrm{OH})$ d'Alcools Primaires en Solvants Inertes, J. Raman Spectrosc. 7 (1978) 173-177.

[9] J. P. Perchard, C. Perchard, A. Burneau, Raman Spectroscopy of Weak Hydrogen Bonds in the Liquid Phase, J. Mol. Struct. 47 (1978) 285-290.

[10] B. Desbat and J.-C. Lassègues, Raman Spectra of the Dimethyl Ether...Hydrogen Chloride Hydrogen-Bonded Complex in the Gas Phase, J. Chem. Phys. 70 (1979) 1824-1829.

[11] Burneau, J. P. Perchard, G. Zuppiroli, J. Limouzi and E. Maréchal, Effect of Electrical Anharmonicity on the Profiles of H-Bonded $\mathrm{OH}$ and $\mathrm{SH}$ stretching bands, Mol. Phys. 41 (1980) 1373-1386.

[12] S. Bratos, Infrared Band Shaped of van ver Waals and Hydrogen Bonded Liquids. Comparison of Band Shaping Mechanisms, Croatica Chemica Acta 55 (1982) 1522.

[13] Y. Maréchal, La Mécanique de la Liaison Hydrogène: Résultats de Spectroscopie Infrarouge, Can. J. Chem. 63 (1985) 1684-1688.

[14] O. Henri-Rousseau and P. Blaise, in: D. Hadzi (Ed.), Theoretical Treatment of Hydrogen bonding, John Wiley, 1997, p. 165 
[15] P. Asselin, B. Dupuis, J. P. Perchard, P. Soulard, The Gas Phase Infrared Spectrum of $\mathrm{HCl}$ Complexed with Dimethyl Ether Revisited: Assignment of the Fundamental Transition from a Jet-Cooled Experiment, Chem. Phys. Lett. 268 (1997) 265-272

[16] P. Asselin, P. Soulard, M. E. Alikhani, J. P. Perchard, A New Interpretation of the IR Spectrum of $\mathrm{H}(\mathrm{D}) \mathrm{Cl}$ complexed with Dimethyl Ether from a Supersonic jetFTIR Experiment, Chem. Phys. 249 (1999) 73-77.

[17] P. Asselin, P. Soulard, M. E. Alikhani, J. P. Perchard, Investigation of the Gas Phase Infrared Spectrum of HF complexed with Dimethyl Ether from both Celland Supersonic jet-FTIR Experiment, Chem. Phys. 256 (2000) 195-205.

[18] K. Heyne, N. Huse, J. Dreyer, E. T. J. Nibbering, T. Elsaesser, S. Mukamel, Coherent Low-Frequency Motions of Hydrogen Bonded Acetic Acid Dimers in the Liquid Phase, J. Chem. Phys., 121 (2004) 902-913.

[19] G. S. Denisov, J. Mavri and L. Sobczyk, in: S. J. Grabowski (Ed.) Hydrogen Bonding- New Insights, Springer, 2006, p. 377.

[20] Y. Maréchal, The Hydrogen Bond and the Water Molecule, Elsevier, 2007, 115139.

[21] N. Rekik, H. Ghalla and G. Hanna, Explaining the Structure of the OH Stretching Band in the IR Spectra of Strongly Hydrogen-Bonded Dimers of Phosphinic Acid and Their Deuterated Analogs in the Gas Phase: A Computational Study, J. Phys. Chem. A 116 (2012) 4495-4509.

[22] N. Rekik, J. Suleiman, P. Blaise, M. J. Wojcik, H.T. Flakus and T. Nakajima, Electrical Anharmonicity in Hydrogen Bonded systems: Complete Interpretation of the IR Spectra of Cl-H stretching band in the Gaseous $\left(\mathrm{CH}_{3}\right)_{2} \mathrm{O} \cdots \mathrm{HCl}$ Complex, Phys. Chem. Chem. Phys. 19 (2017) 5917 and references there in.

[23] J. Murto, A. Kivinen, J. Korppi-Tommola, R. Viitala, J. Hyomaki, Acta Chem. Scand. 27 (1973) 107-120.

[24] J. Korppi-Tommola, Association of tert-Butyl Alcohol: a Matrix Infrared Study, J. Mol. Struct. 40 (1977) 13-23.

[25] J. Korppi-Tommola, Tert-Butyl Alcohol - Matrix I.R. Spectra and Vibration Assignment, Spectrochimica Acta 34A (1978) 1077-1085.

[26] O. Schrems, H. M. Oberhoffer and W. A. P. Luck, Infrared Studies of Fluoroalcohol-base complexes in the GasPhase, Carbon Tetrachloride Solutions and Argon Matrices, J. Molec. Structure 80 (1982) 129-134.

[27] L. Schriver, A. Burneau and J. P. Perchard, Infrared Spectrum of the Methanol Dimer in Matrices. Temperature and Irradiation Effects in Solid Nitrogen, J.Chem.Phys. 77 (1982) 4926-4832.

[28] O. Schrems, H. M. Oberhoffer and W. A. P. Luck, Hydrogen Bonding in LowTemperature Matrices: 1. Proton Donor Abilities of Fluoroalcohols. Comparative Infrared Studies of $\mathrm{ROH} \cdots \mathrm{O}\left(\mathrm{CH}_{3}\right)_{2}$ Complex Formation in the Gas Phase, in CCl4 Solution, and in SolidArgon, J. Phys. Chem. 88 (1984) 4335-4342.

[29] W. A. P. Luck and H.Y. Zheng, Effects of Solvents and Temperature on O-H Stretching Band of Methanol: Measure of Van der Waals Interactions, Z. Naturforsch. 39 a (1984) 888-892. 
[30] L. Schriver and A. Burneau, Infrared Spectroscopic Study of Intermolecular Effects on the Conformational Isomerism of Monomer and Dimer Perfluoro-t-buryl Alcohol in Mixed Matrices, J. Chem. Soc. Faraday Trans. 281 (1985) 503-516.

[31] O. Schrems, IR-laser induced interconversiosn of Hydrogen-Bonded Dimers in Cryogenics Matrices, J.Mol. Struct. 141 (1986) 451-456.

[32] H. Kleeberg, D. Klein and W. A. P. Luck, Quantitative Infrared Spectroscopic Investigations of Hydrogen-Bond Cooperativity, J. Phys. Chem.91 (1987) 32003203 .

[33] L. England-Kretzer, M. Fritzche and W. A. P. Luck, The Intensity Change of IR Bands by H-Bonds, J. Mol. Struct. 175 (1988) 277-282.

[34] W. A. P. Luck and S. Peil, IR Studies of Van der Waals Interactions on Perfluoro-tButyl Alcohol OH. I. Environments Effects on Monomeric $\mathrm{OH}^{*}$ and SelfAssociates, J. Mol. Struct. 224 (1990) 175-184.

[35] W. A. P. Luck and S. Peil, IR Studies of Van der Waals Interactions on Perfluoro-tButyl Alcohol OH. II. Complexes with Acetonitrile, J.Mol. Struct. 224 (1990) 185202.

[36] L. Schriver, A. Schriver, S. Peil and O. Schrems, Hydrogen-bonded Complexes of Perfluoro-t-butanol with Acetone and Nitromethane in Low Temperature Solutions and Matrices, Can. J. Chem. 69 (1991) 1520-1527.

[37] W. A. P. Luck and S. Peil, Spectroscopic Investigations of Intermolecular Interactions between Different Parts of Molecules, Z. Naturforsch. 46a (1991) 4348 .

[38] A. Karmakar, S. Sarkar and R. Joarder, Molecular Clusters in Liquid tert-Butyl Alcohol at Room Temperature, J. Phys. Chem. 99 (1995) 16501-16503.

[39] N. Bakkas, Y. Bouteiller, A. Loutellier, J. P. Perchard, S. Racine, The WaterMethanol Complexes. Matrix induced structural conversion of the 1-1 Species, Chem. Phys. Lett. 232 (1995) 90-98.

[40] J. R. Dixon, W. O. George, Md. F. Hossain, R. Lewis and J. M. Price, Hydrogenbonded forms of methanol. IR spectra and ab initio calculations, J. Chem. Soc., Faraday Trans. 93 (1997) 3611-3618.

[41] G. Larsen and Z. K. Ismail, Monomeric tert-Butanol in Benzene and Cyclohexane Solutions: a Fourier-Transform Infrared Spectroscopy Study, J. Sol. Chem. 27, 810 (1998).

[42] G. Larsen, Z. K. Ismail, B. Herreros and R. D. Parra, Benzene/tert-Butyl Alcohol Interactions. 1. A Theoretical and Experimental Study, J. Phys. Chem. A 102 (1998) 4734-4741.

[43] D. T. Bowron, J. L. Finney and A. K. Soper, The Structure of Pure Tertiary Butanol, Mol. Phys. 93 (1998) 531-543.

[44] M. A. Czarnecki, H. Maeda and Y. Ozaki, Resolution Enhancement and Band Assignments for the First Overtone of OH Stretching Modes of Butanols by TwoDimensional Near-Infrared Correlation Spectroscopy. 2.Thermal Dynamics of Hydrogen Bonding in $n$ - and tert-Butyl Alcohol in the Pure Liquid States, J. Phys. Chem. A 102 (1998) 9117-9123. 
[45] O. Kristianssen, Investigation of the $\mathrm{OH}$ Stretching Vibration of $\mathrm{CD}_{3} \mathrm{OH}$ in $\mathrm{CCl}_{4}, \mathrm{~J}$. Mol. Struct. 477 (1999) 105-111.

[46] A. Burneau, F. Génin, F. Quilès, Ab initio Study of the Vibrational Properties of Acetic Acid Monomers and Dimers, Phys. Chem.Chem. Phys. 2 (2000) 5020-5029.

[47] S. Sarkar, P. P. Nath and R. N. Joarder, Orientation Correlation versus Cluster Correlation in Molecular Liquids-signature through diffraction data, Phys. Letts. A 275 (2000), 138-141.

[48] P. G. Kusalik, A. P. Lyubartev, D. L. Bergman and A. Laaksonen, Computer Simulation Study of tert-Butyl Alcohol. I. Structure in the Pure Liquid, J. Phys. Chem. B 104 (2000) 9526-9532.

[49] P. G. Kusalik, A. P. Lyubartev, D. L. Bergman and A. Laaksonen, Computer Simulation Study of tert-Butyl Alcohol. II. Structure in Aqueous Solution, J. Phys. Chem. B 104 (2000) 9533-9539.

[50] A. Chen, J. Potoff and J. Siepmann, Monte Carlo Calculations for Alcohols and Their Mixtures with Alkanes. Transferable Potentials for Phase Equilibria. 5. United-Atom Description of Primary, Secondary, and Tertiary Alcohols J. Phys. Chem. B 105 (2001) 3093-3104.

[51] J. P. Perchard, Z. Mielke, Anharmonicity and Hydrogen Bonding-. I. A NearInfrared study of Methanol trapped in Nitrogen and Argon Matrices, Chem. Phys. 264 (2001) 221-234.

[52] P. P. Nath, S.Sarkar, P. S. R. Krishna and R. N. Joarder, Intermolecular structure of liquid D-tert-butanol by neutron-diffraction data, Appl. Phys. A 74, S348 (2002).

[53] P. K. Kipkemboi, P. C. Kiprono and J. J. Sanga, Vibrational Spectra of t-Butyl Alcohol, t-Butylamine and t-Butyl Alcohol + t-Butylamine Binary Liquid Mixtures, Bull. Chem. Soc. Ethiop. 17, 211 (2003).

[54] F. Aliotta, M. Musso, R. Ponterio, F. Saija, and G. Salvato, Evidence of Heterogeneous Aggregation in Methanol/CCl4 Mixtures: A Brillouin Scattering Investigation, J. Phys. Chem. B, 108 (2004) 12972-12977.

[55] M. Broquier, C. Crépin, A. Cuisset, H. Dubost and J. P. Galaup, Influence of a Weak Hydrogen Bond on Vibrational Coherence Probed by Photon Echoes in DCl Dimer Trapped in Solid Nitrogen, J. Phys.Chem. A, 109 (2005) 4873-4880.

[56] J.-M. Andanson, J.-C. Soetens, T. Tassaing and M. Besnard, Hydrogen Bonding in Supercritical tert-Butanol Assessed by Vibrational Spectroscopies and Molecular Dynamics Simulations, J. Chem. Phys. 122 (2005) 174512-9.

[57] F. Palombo, M. Paolantoni, P. Sassi and A. Morresi, Spectroscopic studies of the “free', OH stretching bands in liquid alcohols, J. Mol. Liq. 125 (2006) 139-146.

[58] P. Sassi, F. Palombo, R. S. Cataliotti, M. Paolantoni and A. Morresi, Distributions of H-Bonding Aggregates in tert-Butyl Alcohol: The Pure Liquid and Its Alkane Mixtures, J. Phys. Chem. A 111, (2007) 6020-6027.

[59] A. Perera, F. Sokolic and L. Zoranic, Microstructure of neat alcohols, Phys. Rev. E. 75 (2007) 060502(R) 1-4. 
[60] L. Zoranic, F. Sokolic and A. Perera, Microstructure of neat alcohols: A molecular dynamics study, J. Chem. Phys. 127 (2007) 024502-10.

[61] A. Vuluga, J. Legros, B. Crousse, A. M. Z. Slawin, C. Laurence, P. Nicolet and D. Bonnet-Delpon, J. Org. Chem. 76, 1126 (2011).

[62] G. A. Pitsevich, I. Yu. Doroshenko, V. Ye. Pogorelov, D. S. Umrejko, Quantum Chemical Simulation and Low- Temperature FTIR investigations of the Structure and Spectral Chracteristics of Methanol Monomer and Dimer in an Argon Matrix, J. Spectrosc. Dyn. 1:9 (2011) 1-16.

[63] P. Sillrén, J. Bielecki, J. Mattsson, L. Börjesson and A. Matic, A statistical model of hydrogen bond networks in liquid alcohols, J. Chem Phys. 136 (2012), 0945147.

[64] A. R. Abdel Hamid, R. Lefort, Y. Lechaux, A. Moréac, A. Ghoufi, C. AlbaSimionesco and D. Morineau, Solvation Effects on Self-Association and Segregation Processes in tert-Butanol - Aprotic Solvent Binary Mixtures, J. Phys. Chem. B 117 (2013) 10221-10230.

[65] F. Kollipost, K. Papendorf, Yu-F. Lee, Yuan-P. Lee and M. A. Suhm, Alcohol dimers - how much diagonal $\mathrm{OH}$ anharmonicity? Phys. Chem. Chem. Phys. 16 (2014) 15948-15956.

[66] R. E. Asfin, IR Spectra of Hydrogen-Bonded Complexes of Trifluoroacetic Acid with Acetone and Diethyl Ether in Gas Phase. Interaction between $\mathrm{CH}$ and $\mathrm{OH}$ Stretching Vibrations, J. Phys. Chem. A 123 (2019) 3285-3292.

[67] B. Yang, X. Cao, H. Lang, S. Wang, C. Sun, Study on Hydrogen Bonding Network in Aqueous Methanol Solution by Raman Spectroscopy, Spectrochimica Acta 225 A (2020) 117488.

[68] O. Henri-Rousseau, D. Chamma, IR spectral density of weak H-bonded complexes involving damped Fermi resonances. I. Quantum theory, Chem. Phys. 229 (1998) $37-50$.

[69] O. Henri-Rousseau, P. Blaise, D. Chamma in: I. Prigogine, Stuart A. Rice (Eds.) Advances in Chemical Physics, Vol. 121, 2002, p. 241-309.

[70] L. Knunyants and B. L. Dyatkin, Izv. Akad. Nauk. USSR, Chem. Ser. 923 (1964).

[71] G. Gilli, P. Gilli, The Nature of the Hydrogen Bond: Outline of a Comprehensive Hydrogen Bond Theory, Oxford 2009, p.177-184.

[72] A. P. Serjeant and B. Dempsey, IUPAC Chemical Data Series 23, 989, Pergamon Press, NewYork,. (1979).

[73] P. Morgado, L. F. G. Martins, Eduardo J. M. Filipe, From nano-emulsions to phase separation: Evidence of nano-segregation in (Alkane + Perfluoroalkane) mixtures using ${ }^{129}$ Xe NMR Spectroscopy, PCCP, 2019, 21, 3742-3751.

[74] P. Duarte, M. Silva, D. Rodrigues, P. Morgado, L. F. G. Martins, E. J. M. Filipe, Liquid Mixtures Involving Hydrogenated and Fluorinated Chains: (p, P, T, X) 
Surface of (Ethanol + 2,2,2-Trifluoroethanol), Experimental and Simulation. J. Phys. Chem. B 2013, 117, 9709-9717.

[75] P. Morgado, A. R. Garcia, L. F. G. Martins, L. M. Ilharco, Eduardo J. M. Filipe, Alkane Coiling in Perfluoroalkane Solutions: A New Primitive Solvophobic Effect, Langmuir, 2017, 33, 11429-11435

[76] G. M. C. Silva, P. Morgado, E. J. M. Filipe, Towards Aqueous - fluorous hydrogenous emulsions: phase equilibria and liquid structure of (water $+1 \mathrm{H}, 1 \mathrm{H}-$ Perfluorobutanol + 1-Butanol) ternary mixture., Fluid Phase Equilibria, 2020, xxx, xxx-Xxx.

[77] M. J. Frisch, G. W. Trucks, H. B. Schlegel, G. E. Scuseria, M. A. Robb, J. R. Cheeseman, G. Scalmani, V. Barone, B. Mennucci, G. A. Petersson, H. Nakatsuji, M. Caricato, X. Li, H. P. Hratchian, A. F. Izmaylov, J. Bloino, G. Zheng, J. L. Sonnenberg, M. Hada, M. Ehara, K. Toyota, R. Fukuda, J. Hasegawa, M. Ishida, T. Nakajima, Y. Honda, O. Kitao, H. Nakai, T. Vreven, J. A. Montgomery, Jr., J. E. Peralta, F. Ogliaro, M. Bearpark, J. J. Heyd, E. Brothers, K. N. Kudin, V. N. Staroverov, R. Kobayashi, J. Normand, K. Raghavachari, A. Rendell, J. C. Burant, S. S. Iyengar, J. Tomasi, M. Cossi, N. Rega, J. M. Millam, M. Klene, J. E. Knox, J. B. Cross, V. Bakken, C. Adamo, J. Jaramillo, R. Gomperts, R. E. Stratmann, O. Yazyev, A. J. Austin, R. Cammi, C. Pomelli, J. W. Ochterski, R. L. Martin, K. Morokuma, V. G. Zakrzewski, G. A. Voth, P. Salvador, J. J. Dannenberg, S. Dapprich, A. D. Daniels, O. Farkas, J. B. Foresman, J. V. Ortiz, J. Cioslowski and D. J. Fox, Gaussian, Inc., Gaussian 09, Revision D.01 (2009).

[78] E. B. Wilson, J. C. Decius and P. C. Cross, Molecular Vibrations, Mc Graw-Hill, New York, 1955.

[79] V. Barone, Anharmonic vibrational properties by a fully automated second-order perturbative approach, J. Chem. Phys. 122, 2005, 014108

[80] A. Novak, Hydrogen bonding in solids. Correlation of spectroscopic and crystallographic data, Struct. Bonding, 18 (1974) 177-216.

[81] E. Libowitzky, Correlation of $\mathrm{OH}$ stretching frequencies and O-H...O hydrogen bond lengths in minerals, Monatshefte für Chemie, 130 (1999) 1047-1059.

[82] M. Rozenberg, A. Loewenschuss and Y. Marcus, An Empirical Correlation between Stretching Vibration Redshift and Hydrogen Bond Length, Phys. Chem. Chem. Phys. 2 (2000) 2699-2702.

[83] H.-W. Wang, M. J. DelloStritto, N. Kumar, A. I. Kolesnikov, P. R. C. Kent, J. D. Kubicki, D. J. Wesolowski, and J. O. Sofo, Vibrational density of states of strongly H-bonded interfacial water: insights from inelastic neutron scattering and theory, J. Phys. Chem. C 118 (2014) 10805-10813.

[84] Yu. A. Galkina, N. A. Kryuchkova, M. A. Vershinin and B. A. Kolesov, Features of strong $\mathrm{O}-\mathrm{H} \cdots \mathrm{O}$ and $\mathrm{N}-\mathrm{H} \cdots \mathrm{O}$ hydrogen bond manifestation in vibrational spectra, J. Structural Chem, 58 (2017) 911-918.

[85] D. Ngo, H. Liu, Z. Chen, H. Kaya, T. J. Zimudzi, S. Gin, T. Mahadevan, J. Du and S. H. Kim, Hydrogen bonding interactions of $\mathrm{H}_{2} \mathrm{O}$ and $\mathrm{SiOH}$ on a boroaluminosilicate glass corroded in aqueous solution, npj Materials Degradation (2020) 4:1-14. 
[86] P. J. Krueger, Double-Minimum Potential for Intramolecularly Hydrogen-Bonded Protons in Ortho-Substituted Anilines, Can. J. Chem. 42 (1964) 201-211

[87] H. Abramczyk, IR $v_{s}(\mathrm{XH})$ Absorption Band Shape of H-Bonded Complex. I. Theory, Chem.Phys. 144 (1990) 305-318

[88] H. Abramczyk, IR $v_{\mathrm{s}}(\mathrm{XH})$ Absorption Band Shape of H-Bonded Complex in Condensed Media. II. Numerical Calculations of the Profiles, Chem.Phys. 144 (1990) 319-326.

[89] M. Goubet, B. Madebène, M. Lewerenz, Coupled Anharmonic Vibrational Dynamics of the Hydrogen Bond in Binary Complexes, Chimia Int. J. Chem. 58 (2004) 291-295.

[90] F. Mariotti, M. Quack, M. Willeke and J. Stohner, Theoretical Chemistry: Molecular Spectroscopy and Dynamics, Chimia 58 (2004) 263-275.

[91] J. Dreyer, Hydrogen-Bonded Acetic Acid Dimers: Anharmonic Coupling and Linear Infrared Spectra Studied with Density-Functional Theory, J. Chem. Phys. 122 (2005) 184306-1-10.

[92] N. Rekik, B. Oujia and M. J. Wojcik, Theoretical Infrared Spectral Density of HBonds in Liquid and Gas Phases: Anharmonicities and Damping Effects, Chem.Phys. 352 (2008) 65-76.

[93] G. N. Robertson and J. Yarwood, Vibrational Relaxation of Hydrogen-Bonded Species in Solution. I. Theory, Chem. Phys. 32 (1978) 267.

[94] J. L. McHale, Molecular Spectroscopy, Prentice Hall, New Jersey, 1999.

[95] W. G. Rothschild, Dynamics of Molecular Liquids, Wiley, New York, 1984.

[96] B. Bagchi, Molecular Relaxation in Liquids, Oxford University Press, New York, 2012, 280-288.

[97] H. J. Bakker and M. Bonn, in: M. Fayer (Ed.) Ultrafast Infrared Vibrational Spectroscopy, CRC Press 2013, p. 104-105.

[98] M. Bonn, M. J. P. Brugmans, A. W. Kleyn, R. A. van Santen and H. J. Bakker, Vibrational Dephasing Mechanisms in Hydrogen-Bonded Systems, Phys. Rev. Lett. 76 (1996) 2440-2443.

[99] E. T. Nibbering, J. Dreyer, O. Kühn, J. Bredenbeck, P. Hamm, T. Elsaesser, in: O. Kühn, L. Wöste (eds.) Analysis and Control of Ultrafast Photoinduced Reactions. Chemical Physics, vol 87, Springer, Berlin, Heidelberg 2007, p. 619-687. 


\section{Declaration of interests}

૫ The authors declare that they have no known competing financial interests or personal relationships that could have appeared to influence the work reported in this paper.

$\square$ The authors declare the following financial interests/personal relationships which may be considered as potential competing interests:

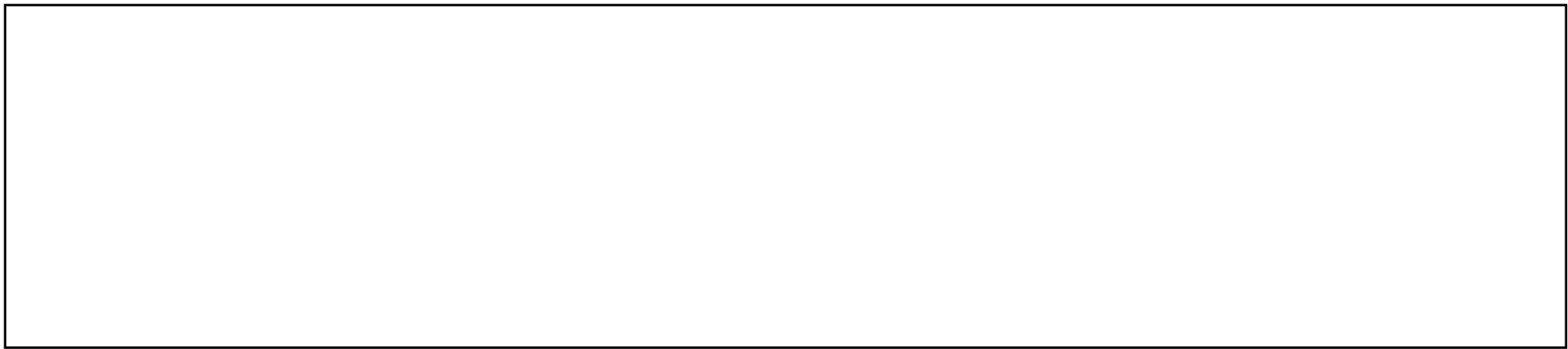




\section{Supporting Information}

Gaseous hetero dimers of perfluoro tert-butyl alcohol with hydrogenated alcohols by infrared spectroscopy

M. Isabel Cabaço ${ }^{a, b^{*}}$, Marcel Besnard ${ }^{a, c}$, Pedro Morgado ${ }^{d}$, Eduardo J. M. Filipe ${ }^{d}$, João A. P. Coutinho $^{\mathrm{e}}$ and Yann Danten ${ }^{\mathrm{c}}$

${ }^{a}$ CeFEMA, Department of Physics, Instituto Superior Técnico, Universidade de Lisboa, Av. Rovisco Pais 1049-001 Lisboa, Portugal

${ }^{b}$ Laboratório de Instrumentação, Engenharia Biomédica e Física da Radiação (LIBPhys-UNL), Departamento de Física, Faculdade de Ciências e Tecnologia, FCT, Universidade Nova de Lisboa, Caparica, Portugal

${ }^{c}$ GSM Institut des Sciences Moléculaires, CNRS (UMR 5255), Université Bordeaux I,351, Cours de la Libération 33405 Talence Cedex, France

${ }^{d}$ Centro de Química Estrutural, Instituto Superior Técnico, Universidade de Lisboa, Av. Rovisco Pais 1049-001 Lisboa, Portugal

${ }^{e}$ CICECO, Departamento de Química, Universidade de Aveiro 3810-193 Aveiro, Portugal

${ }^{f}$ Materials and Engineering Research Institute, Sheffield Hallam University, Howard Street, Sheffield S1 $1 \mathrm{WB}, \mathrm{UK}$ 
Table SI-1: Calculated electron energy $\mathbf{E}^{\circ}$, ZPE-corrected electron energy $\mathbf{E}^{\circ+Z P E}$ and internal energy $\mathbf{E}_{\mathbf{2 9 8 K}}$ (electron and thermal) at $298 \mathrm{~K}$ for TBH, TBF, methanol and 1-butanol monomers and for the stable hetero-dimers formed with TBF at the B3LYP/6-311+G(2d,p) computational level. BSSE-corrected $\Delta \mathbf{E}^{\text {cor }}$ and uncorrected $\Delta \mathbf{E}^{\text {uncor }}$ binding energy of stable hetero-dimers formed with TBF are also given in this.

\begin{tabular}{|c|c|c|c|c|c|}
\hline & $\mathrm{E}^{0}(\mathrm{H})$ & $\mathrm{E}^{0+\mathrm{ZPE}}(\mathrm{H})$ & $E_{298 K}(H)$ & $\begin{array}{c}\Delta \mathrm{E}^{\text {uncor }} \\
\text { (kcal/mol) }\end{array}$ & $\begin{array}{c}\Delta \mathrm{E}^{\mathrm{cor}} \\
\text { (kcal/mol) }\end{array}$ \\
\hline \multicolumn{6}{|l|}{ Monomers } \\
\hline TBH & -233.75733 & -233.62247 & -233.65151 & & \\
\hline TBF & -1127.21180 & -1127.14660 & -1127.18595 & & \\
\hline methanol & -115.76762 & -115.71655 & -115.71318 & & \\
\hline 1-butanol & -233.74743 & -233.610783 & -233.60401 & & \\
\hline \multicolumn{6}{|l|}{ Hetero-dimers } \\
\hline TBF-methanol & -1242.99439 & -1242.87625 & -1242.85886 & -9.4 & -9.3 \\
\hline TBF-Butanol & -1360.97359 & -1360.77012 & -1360.74912 & -9.4 & -9.3 \\
\hline TBF-TBH & -1360.98475 & -1360.78321 & -1360.83663 & -9.8 & -9.7 \\
\hline
\end{tabular}

Table SI-2: Calculated Harmonic and Anharmonic vibrational transitions and IR intensities, associated with the $v_{\mathrm{OH}}$ stretching modes of tert-butanol (TBH), perfluoro tert-butanol (TBF), methanol and 1-butanol monomers and for stable hetero-dimers formed with TBF in gas phase at the B3LYP/6-311+G(2d,p) computational level.

\begin{tabular}{|c|c|c|c|c|}
\hline & \multicolumn{2}{|c|}{$\begin{array}{c}\text { Calc. }(\mathrm{OH}) \text { vibrations } \\
\left(\mathbf{c m}^{-1}\right)\end{array}$} & \multicolumn{2}{c|}{$\begin{array}{c}\text { Calc. IR Intensities } \\
\text { (km/mol) }\end{array}$} \\
\hline Species & Anharm & Harm & Anharm & Harm \\
\hline Monomers & & & & \\
\hline TBH & 3644.9 & 3812.2 & 11.8 & 13.9 \\
\hline TBD9 & 3644.5 & 3812.2 & 10.3 & 13.9 \\
\hline TBF & 3612.5 & 3792.8 & 83.3 & 90.3 \\
\hline CH3OH & 3655.9 & 3841.2 & 26.6 & 31.0 \\
\hline CD3OH & 3655.9 & 3841.1 & 26.2 & 31.6 \\
\hline 1-Butanol & 3670.6 & 3842.4 & 25.6 & 32.8 \\
\hline \hline Hetero-Dimers & & & & 1566.0 \\
\hline TBF-TBH & 3034.1 & 3274.5 & 641.0 & 28.2 \\
\hline TBF-TBD9 & 3624.9 & 3804.7 & 23.1 & 1575.7 \\
& 3042.7 & 3274.3 & 620.3 & 28.1 \\
\hline TBF-CH3OH & 3627.6 & 3804.4 & 23.2 & 1313.2 \\
& 3648.7 & 3326.2 & 892.3 & 52.9 \\
\hline TBF-CD3OH & 3117.8 & 3325.6 & 890.5 & 1324.7 \\
& 3649.3 & 3833.0 & 42.9 & 53.4 \\
\hline TBF-1-Butanol & 3041.3 & 3211.9 & 467.7 & 1300.8 \\
& 3652.6 & 3826.6 & 37.1 & 61.5 \\
\hline
\end{tabular}


Table SI-3: Idem Table SI-2 for the $\gamma_{\mathrm{OH}}$ torsional modes of alcohols monomers and heterodimers formed with TBF

\begin{tabular}{|c|c|c|c|c|}
\hline \multirow{2}{*}{\multicolumn{2}{|l|}{ Calc. 1OH) vibrations (cm-1) }} & \multicolumn{2}{c|}{$\begin{array}{c}\text { Calc. IR Intensities } \\
\text { (km/mol) }\end{array}$} \\
\hline Species & Anharm & Harm & Anharm & Harm \\
\hline monomers & & & & \\
\hline TBH & 439.3 & 284.1 & 2.3 & 67.7 \\
\hline TBD9 & 90.8 & 269.6 & 42.7 & 80.9 \\
\hline TBF (a) & 235.3 & 283.5 & 33.5 & 37.5 \\
& 308.2 & 299.3 & 6.1 & 49.8 \\
& 396.9 & 328.0 & 109.0 & 22.9 \\
\hline CH3COH & 226.5 & 294.1 & 107.8 & 120.6 \\
\hline CD3COH & 211.3 & 279.0 & 114.9 & 129.8 \\
\hline Hetero-Dimers ${ }^{\text {(b) }}$ & & & & \\
\hline TBF-TBH & 349.2 & 386.3 & 4.7 & 4.9 \\
& 403.9 & 367.9 & 4.2 & 50.8 \\
\hline TBF-TBD9 & 312.3 & 349.6 & 21.2 & 28.6 \\
& 380.9 & 354.6 & 23.9 & 7.3 \\
\hline TBF-CH3OH & 325.3 & 367.4 & 5.1 & 58.2 \\
& 466.4 & 402.2 & 67.5 & 79.7 \\
\hline TBF-CD3OH & 355.2 & 364.7 & 6.6 & 66.5 \\
& 457.7 & 398.9 & 107.4 & 70.5 \\
\hline
\end{tabular}

(a) From anharmonic analysis of TBF monomer, the $\gamma_{\mathrm{OH}}$ torsion is coupled with $\rho\left(\mathrm{CF}_{3}\right)$ rocking modes. Thus, the vibrational transition of the $\gamma_{\mathrm{OH}}$ mode is decomposed in two components at 235.3 and $308.2 \mathrm{~cm}^{-1}$ to compare to the experimental transition observed at $252 . \mathrm{cm}^{-1}$.

(b) In hetero-dimers, the $\gamma_{\mathrm{OH}}$ torsion of TBF interacting with hydrogenated alcohol cannot be disentangled because it is mixed with other low frequency intermolecular modes due to the dimer formation. In this table, we provide the predicted transition of $\gamma_{\mathrm{OH}}$ torsion associated with the hydrogenated alcohol partner which can be perceived in two components due to couplings with others modes.

It is noteworthy that a predicted negative combination between the $v_{\mathrm{OH}}$ stretching and $\gamma_{\mathrm{OH}}$ torsion modes of hydrogenated alcohol engaged in the complex with TBF is possible from each components. Nevertheless, we are unable to predict from the anharmonic analysis the IR intensity associated with such a combination. 
Table SI-4: Calculated harmonic and anharmonic transitions and IR intensities corrected from the anharmonicity $(\mathrm{km} / \mathrm{mol})$ associated with the low frequency modes involving $\mathrm{CF}_{3}$ groups of perfluoro tert-butanol (TBF) under monomeric form and engaged in stable hetero-dimers formed with tert-butanol (TBH), methanol and 1-butanol at the B3LYP/6-311+G(2d,p) computational level.

\begin{tabular}{|c|c|c|c|c|c|c|c|c|c|c|c|}
\hline \multicolumn{3}{|c|}{ TBF monomer } & \multicolumn{3}{|c|}{ TBF-TBH } & \multicolumn{3}{|c|}{ ТВF-CH ${ }_{3} \mathrm{OH}$} & \multicolumn{3}{|c|}{ TBF-1-Butanol } \\
\hline Anharm & Harm. & Int & Anharm & Harm. & Int & Anharm & Harm. & Int & Anharm & Harm. & Int \\
\hline 49.7 & 50.8 & 0.2 & 38.7 & 58.8 & 0.1 & 85.8 & 58.6 & 1.8 & 53.4 & 55.1 & 0.1 \\
\hline 68.5 & 67.4 & 0.4 & 55.0 & $70.6^{(\mathbf{b})}$ & 3.6 & 232.5 & $71.6^{(\mathbf{c})}$ & 27.5 & 61.2 & 67.3 & $\sim 0.0$ \\
\hline 73.8 & 73.6 & 0.1 & 59.7 & 75.2 & 0.2 & 110.7 & 79.3 & 2.9 & 71.2 & 75.9 & 0.9 \\
\hline 157.0 & 159.8 & 0.4 & 152.7 & 158.7 & 0.1 & 154.2 & 158.6 & 1.1 & 162.0 & 164.4 & 0.2 \\
\hline 158.9 & 162.3 & 0.3 & 159.3 & $169.9^{\text {(a) }}$ & 2.6 & 203.3 & $181.0^{\text {(d) }}$ & 32.2 & 177.3 & 169.5 & 0.2 \\
\hline 188.2 & 189.4 & 1.5 & 186.9 & $192.0^{\text {(a) }}$ & 3.2 & 177.5 & $194.5^{\text {(d) }}$ & 2.2 & 186.6 & 194.7 & 4.9 \\
\hline
\end{tabular}

(a) coupled with intermolecular OH..O among others entangled modes due to the formation of the complex TBF-TBH.

(b) coupled with relative reorientational motions of both partners engaged in the dimer TBF-TBH.

(c) coupled with relative reorientational motions of methanol engaged in the dimer.

(d) coupled with intermolecular $\mathrm{OH} . . \mathrm{O}$ among others entangled modes due to the formation of the complex.

Table SI.5. Analysis of the experimental profiles of the $v_{\mathrm{OH}}$ vibrational transition of TBF in the heterodimers using a Voigt profile. (G) and (L) are the Gaussian and Lorentzian contributions in the FWHH of the fitted profile, respectively.

\begin{tabular}{|c|c|c|}
\hline & $\begin{array}{c}\mathrm{G} \\
\left(\mathrm{cm}^{-1}\right)\end{array}$ & $\begin{array}{c}\mathrm{L} \\
\left(\mathrm{cm}^{-1}\right)\end{array}$ \\
\hline TBF-CH & & 70 \\
\hline TBF-CD & 21 & 75 \\
\hline TBF-1-Butanol & 24 & 80 \\
\hline TBF-TBH & 47 & 90 \\
\hline TBF-TBD9 & 59 & 90 \\
\hline
\end{tabular}




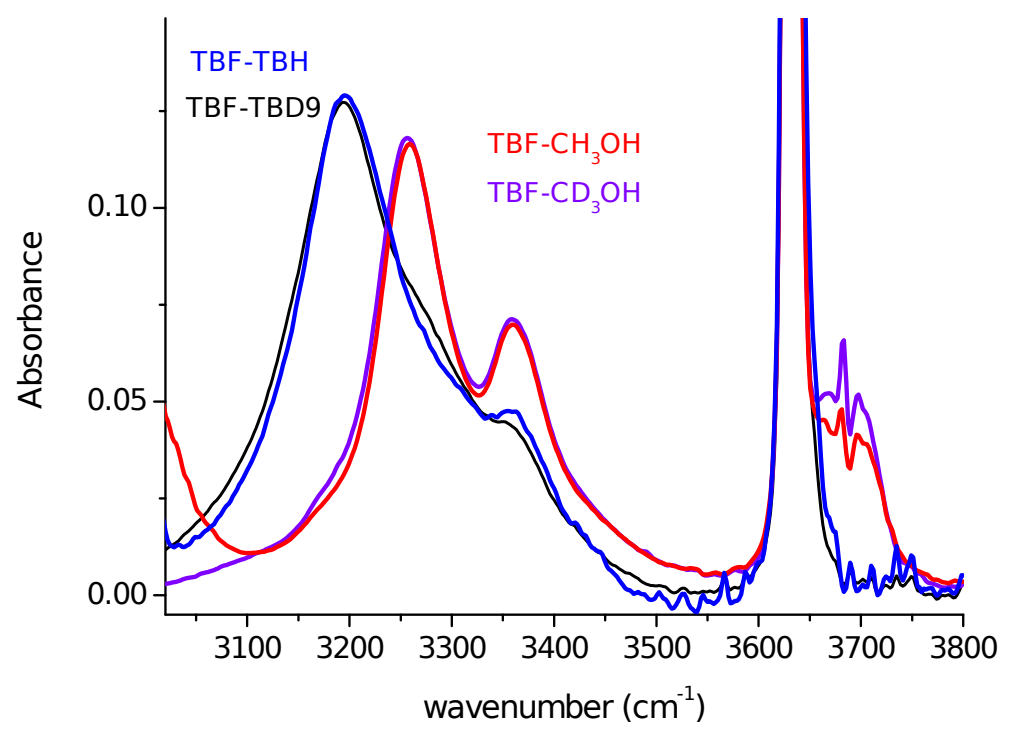

Figure SI.1. Infrared spectra in the domain of the $\mathrm{OH}$ stretching vibration of the gaseous mixtures of TBF-TBH (blue) and $\mathrm{TBF}-\mathrm{CH}_{3} \mathrm{OH}$ (red) compared with those of TBF-TBD9 (black) and TBF- $\mathrm{CD}_{3} \mathrm{OH}$ (violet), respectively.

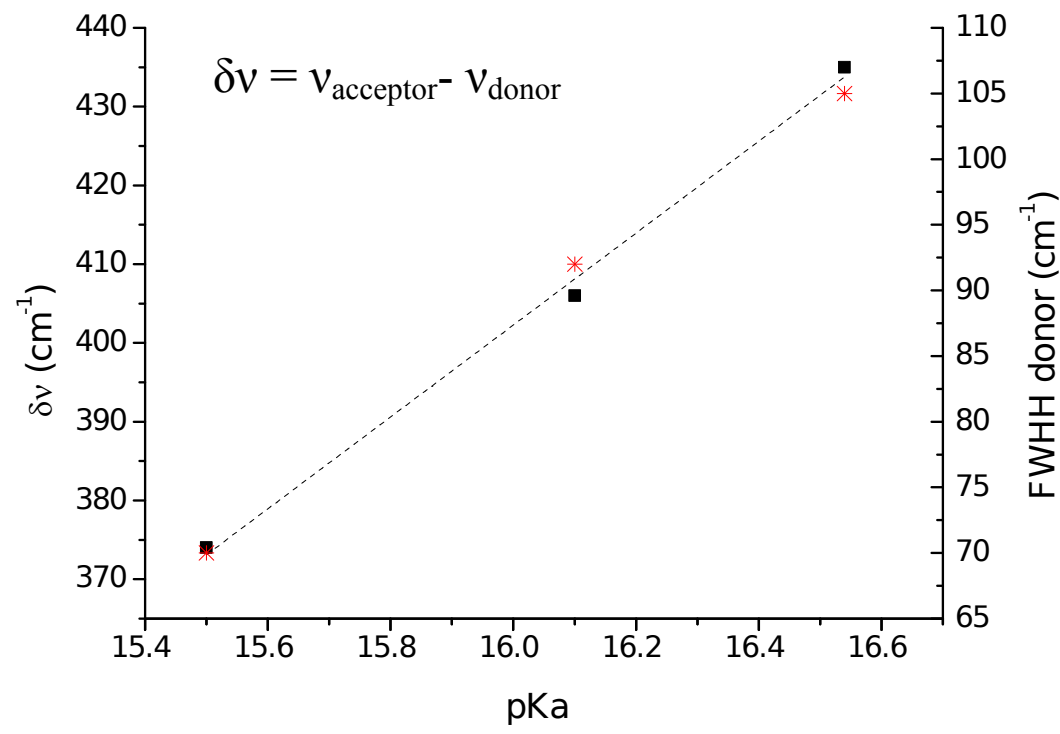

Figure SI.2. Frequency shift $\boldsymbol{\delta} \boldsymbol{v}=\boldsymbol{v}_{\text {acceptor }}-\boldsymbol{v}_{\text {donor }}$ (black) and FWHH of the donor $\boldsymbol{v}_{\mathrm{OH}}$ vibration (red) as a function of the $\mathrm{pKa}$ value of the acceptor alcohol. 


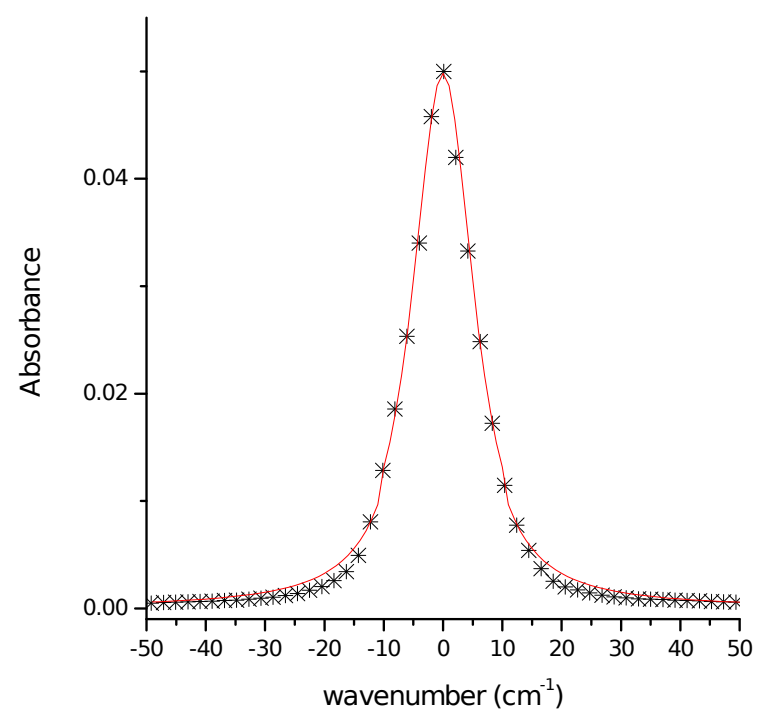

Figure SI.3. Comparison of the experimental profile of the $v_{\mathrm{OH}}$ vibration of pure gaseous TBF (*) with the Voigt profile (red line) resulting from the convolution of a Gaussian function simulating the slit $\left(\mathrm{FWHH}=4 \mathrm{~cm}^{-1}\right)$ with a Lorentzian profile $\left(\mathrm{FWHH}=10 \mathrm{~cm}^{-1}\right)$. 